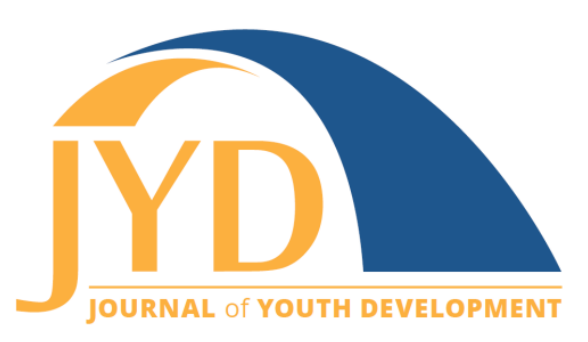

http://jyd.pitt.edu/ | Vol. 15 Issue 1 DOI 10.5195/jyd.2020.824 | ISSN 2325-4017 (online)

\title{
Preparing Capable Youth Workers: The Project Youth Extension Service Approach
}

\author{
Benjamin Silliman \\ North Carolina State University \\ ben_silliman@ncsu.edu \\ Harriett C. Edwards \\ North Carolina State University \\ harriett_edwards@ncsu.edu \\ James C. Johnson \\ North Carolina State University \\ jcjohns7@ncsu.edu
}

\begin{abstract}
The Project Youth Extension Service (YES!) college student internship integrates pre-service training on youth worker competencies with a year or more of practice experience in leading positive youth development programs for military youth impacted by the military deployment process. For nearly a decade, interns have reported significant improvement in 37 behavioral competencies, with 24 indicators improving .50 or more on a 5-point scale. Areas of greatest growth include practices critical to youth worker effectiveness and program quality: self-regulation, interaction, and adaptation in high-intensity settings. Qualitative comments indicate growth in personal maturity (e.g., composure, flexibility, openness to feedback) as well as professional growth (e.g., listening, organization, presentation, teamwork), and empathy for youth and families under stress. Intern growth was also observed by trainers and mentors. Program feedback from youth and event coordinators was consistently positive. Interns also benefited from working with a career mentor. Blended online and on-site training, episodic scheduling, and scaffolded leadership offer effective and efficient methods for programming and professional development. Findings point to the value of intensive and extended training focused on experiential learning, critical reflection, and mentoring, together with background knowledge on military culture, military family life, and youth development. The program model, full results, conclusions, recommendations for practice, and opportunities for improvement are discussed.
\end{abstract}

Key words: youth worker training, youth work competencies, internship, professional development, military youth

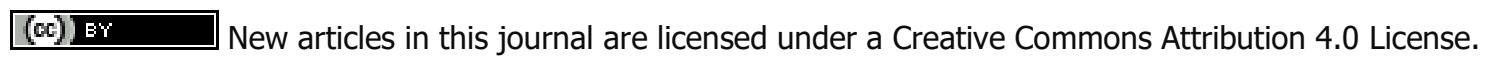
This journal is published by the University Library System, University of Pittsburgh and is cosponsored by the University of Pittsburgh Press. The Journal of Youth Development is the official peer-reviewed publication of the National Association of Extension 4-H Youth Development Professionals and the National AfterSchool Association. 
Capable youth workers (YW) foster youth program quality, continuity, impact, and sustainability (Durlak, Weissberg, \& Pachan, 2010; Garst, Weston, Bowers, \& Quinn, 2019; Smith, Peck, Denault, Blazevski, \& Akiva, 2010). Training and retaining YW is an enduring challenge (Akiva, Li, Martin, Horner, \& McNamara, 2017; Carnegie Commission, 1992; Hartje, Evans, Killian, \& Brown, 2008). Two decades ago, emerging research and practice and expansion of youth development (YD) programs (Borden, Craig, \& Villaruel, 2004; Mahoney, Parente, \& Zigler, 2009) provided both knowledge base and incentive for development of program standards and provider competencies. Subsequently, professional competencies were identified by youthserving organizations such as 4-H (Stone \& Rennekamp, 2003), professional groups such as National Afterschool Association (2011) and Child and Youth Care Collaborative Board (Curry, Eckles, Stuart, Schneider-Munoz, \& Qaqish, 2013), nonprofits such as the National Institute on Out-of-School Time (Starr, Yohalem, \& Gannett, 2009), and government agencies (i.e., Child Care Resource Center, 2019). Vance's (2010) review of competency frameworks found substantial agreement among diverse frameworks on the importance of child and family development, positive guidance, families and communities, program management, professionalism, and communication. The review also indicated general agreement on developmental domains (i.e., physical, cognitive, social, self), safety and health, curriculum, and diversity, but differing emphases in other areas.

Competency training was soon packaged as a credential. City College of New York supported 223 YW (108 graduates) from 1999 to 2011 in completion of a 12-credit Youth Services Certificate (YSC) including courses in principles (e.g., developmental and program theory), practices (i.e., guidance, teaching, and management processes) and special topics (i.e., cultural competence, special needs, youth risks) (Shockley \& Thompson, 2012). Classes integrated peer networking and reflection on professional experiences. Follow-up evaluation samples were small but suggested that training was relevant, changed practices, aided retention and promotion, and increased motivation and confidence to pursue further education.

The Child and Youth Care Certification Board developed a competency framework with five domains (i.e., professionalism, cultural and human diversity, applied human development, relationship and communication, and developmental practice methods) applicable to a broad range of youth work fields (Mattingly, Stuart, \& VanderVen, 2010). Follow-up research found that certified practitioners, $27 \%$ of 775 study participants, were 2.7 times more likely to be rated as high performers by supervisors than non-certified practitioners (Curry et al., 2013). Certification required several components, including education, experience, completion of the 
certification exam and a professional portfolio. However, inclusion of all components predicted only $17 \%$ of variance in performance ratings.

Competency frameworks provide focus, informed by research and practice, but indicators are often either too vague or too prescriptive (Walker \& Walker, 2012). Professional development models reviewed by Akiva et al. (2017) indicated that general training (GT), typically one-time or short-term topical or activity workshops, were relatively less effective for improving program quality than a more intensive and sustained quality improvement system (QIS) approach using standards-based assessment, planning, training, and consulting. Their strengths-based approach, simple interactions (SI), combined features of QIS with a more context-specific, asset-oriented coaching, in contrast to conventional problem-focused, prescriptive practices for trainees. Coaches facilitated guided reflection with YW using videos of their interactions with children, focused on four themes: connection (affective in-tuneness), reciprocity (balanced roles of engagement), participation (involvement of all children), and progression (incremental challenge). After ten months of weekly guided reflection on videos of YW interactions with children, participants affirmed the value of the learning process and noted improvements that were corroborated by external reviewer observations.

Walker and Walker (2012) identified similar features in three programs that fostered YW practitioner expertise. These included (a) working together, engaging in reflective practice and mutual support from peers and expert coaches; (b) applying diverse perspectives, professional judgment, and practical wisdom to real-world practice dilemmas; and (c) sustained time and practice. They recommend inclusion of guiding principles and ethics and clarification of youth rights. Jonas (2012) notes that embedding core competencies in program and performance management facilitates program quality and YW growth. In the past decade, the focus of YW training began to move from competencies to competence, (Walker \& Gran, 2010) or expertise involving "active integration of knowledge, activities, skills, and moment that together are necessary to do the job that has to be done at high levels of quality and consistency" (Baizerman, 2009, p. 88).

In The Universal Competency Framework (UCF) Bartram (2012) describes this pattern in workforce preparation across a broad range of vocations. Competencies are "sets of behaviours that are instrumental in the delivery of desired results" (p. 3). Competence is "the ability to apply knowledge, understanding, and skills [competencies] in performing to the standards required in employment" (p. 4), typically demonstrated in problem solving to meet changing 
demands. Bartram explains that organizational results flow from matching worker competencies (i.e., job-specific behaviors) and potential (i.e., motives, traits, values, and cognitive abilities). In YD, organizational results include program quality and outcomes (Eccles \& Gootman, 2002; Akiva et al., 2017; Pekel et al., 2018).

These patterns for building competence are evident across related fields. Ash and Clayton (2009) found that service learning internships without critical reflection yielded few insights. Broader research on college internships found the greatest benefits linked to challenges that stretched capacities, personalized mentoring, supported autonomy in taking initiative, and included opportunities to practice problem solving on the job (Velez \& Giner, 2015). Shek and Yu (2016) integrated reflective activities into undergraduate courses to promote cognitive competence critical to positive academic, vocational, and health effects. Activities focused on "know what" (knowledge acquisition), "know how" (process skills), and "know why" (reflection on thinking). Anderson-Nathe (2008) recommended that mentoring of youth workers include (a) space for "not knowing"; (b) collegial support networks; and (c) room to experiment, fail, then critically reflect (in a non-judgmental environment), and move toward competence, with attention to personal growth as well as technical problem-solving.

\section{Project YES!: The Training Model}

Project YES! is an initiative of the U.S. Department of Defense Office of Employer Program and Policy and the U.S. Department of Agriculture's National Institute of Food and Agriculture through a cooperative agreement with the North Carolina State University. The primary objective of the program is to implement a high-quality national internship program engaging college students motivated to serve the needs of National Guard and Reserve Component (RC) military families during all phases of deployment. Specifically, Project YES! interns work with military youth who are between the ages of 6 and 17 years and participating in Yellow Ribbon Reintegration Program (YRRP) events, by facilitating evidence-based educational activities that promote leadership development, life skills, and resilient behaviors. Additionally, Project YES! interns learn how to be effective leaders and to increase their vocational awareness, understanding, and interest in national and international career planning. Project YES! was implemented in 2010 and since that time has employed 167 interns and served more than 27,000 military youth at 895 events nationally and internationally.

Project YES! partners began by developing a comprehensive training and evaluation model based on positive youth development (PYD) and workforce preparation (WP) research and 
practice. Bioecological (Bronfenbrenner \& Morris, 2006) and Community Action (Gambone, Klem, \& Connell, 2002) frameworks served as the program umbrella models (Arnold, 2015), with the goal of introducing challenges and supports designed to promote PYD (Bowers et al., 2010; Eccles \& Gootman, 2002) to interns (via expert trainers and team leaders) and youth (via interns) as appropriate (Scales et al., 2016; Larson, Rickman, Gibbons, \& Walker, 2009). At the program implementation level, interns were prepared to deliver developmentally-appropriate 4H STEM and life skills curricula using experiential methods (Enfield, Schmitt-McQuitty, \& Smith, 2007) and critical reflection (Ash \& Clayton, 2009).

Project YES! staff, in consultation with the General H. Hugh Shelton Leadership Center (leadership consultants) and Haigler Enterprises International, Inc. (workforce consultants) conducted a comparison of youth worker duties as outlined in the Universal Competency Framework (UCF) (Bartram, 2012), U.S. Department of Labor Occupational Information Network (O*NET) (Burrus, Jackson, Xi, \& Steinberg, 2013), and 4-H Professional Research and Knowledge Competencies (Stone \& Rennekamp, 2004), consistent with competency models of that time (Starr et al, 2009), and identified 37 competencies to guide training and assessment. The Project YES! operating and programming model is summarized in Figure 1.

\section{Intern Selection and Assessment}

Interns are recruited from all colleges and universities through nationally accessible internship marketing systems. Applications are screened and candidates intensively interviewed to match their experience, aspirations, and growth potential with program objectives and requirements. Following criminal background checks, internship invitations are extended. Average starting age for interns is 22.8 years, with a range of 19.5 to 42 . During their 12-month appointment time, interns are required to serve on at least one youth event per month. However, many interns request the opportunity to support two monthly events. Approximately $60 \%$ of the interns also request additional years of service. Yellow Ribbon Reintegration Program events are typically 1 to 2 days long and conducted throughout the United States and U.S. territories. Project YES! covers all related expenses (travel, lodging, per diem, etc.). Additionally, interns receive a flatrate stipend for each day they spend actively facilitating youth development activities.

Interns initially complete the 37-item Competency Evaluation developed for the Project YES! model. Results of this assessment drive training priorities during orientation and continuing education events. These results also impact the overall experience by helping inform processes that include developing individual plans for skill-building at events, preparing for and debriefing 
after events, designing professional development projects, and individual coaching and mentoring.

Figure 1. Project YES! Operating and Programming Model

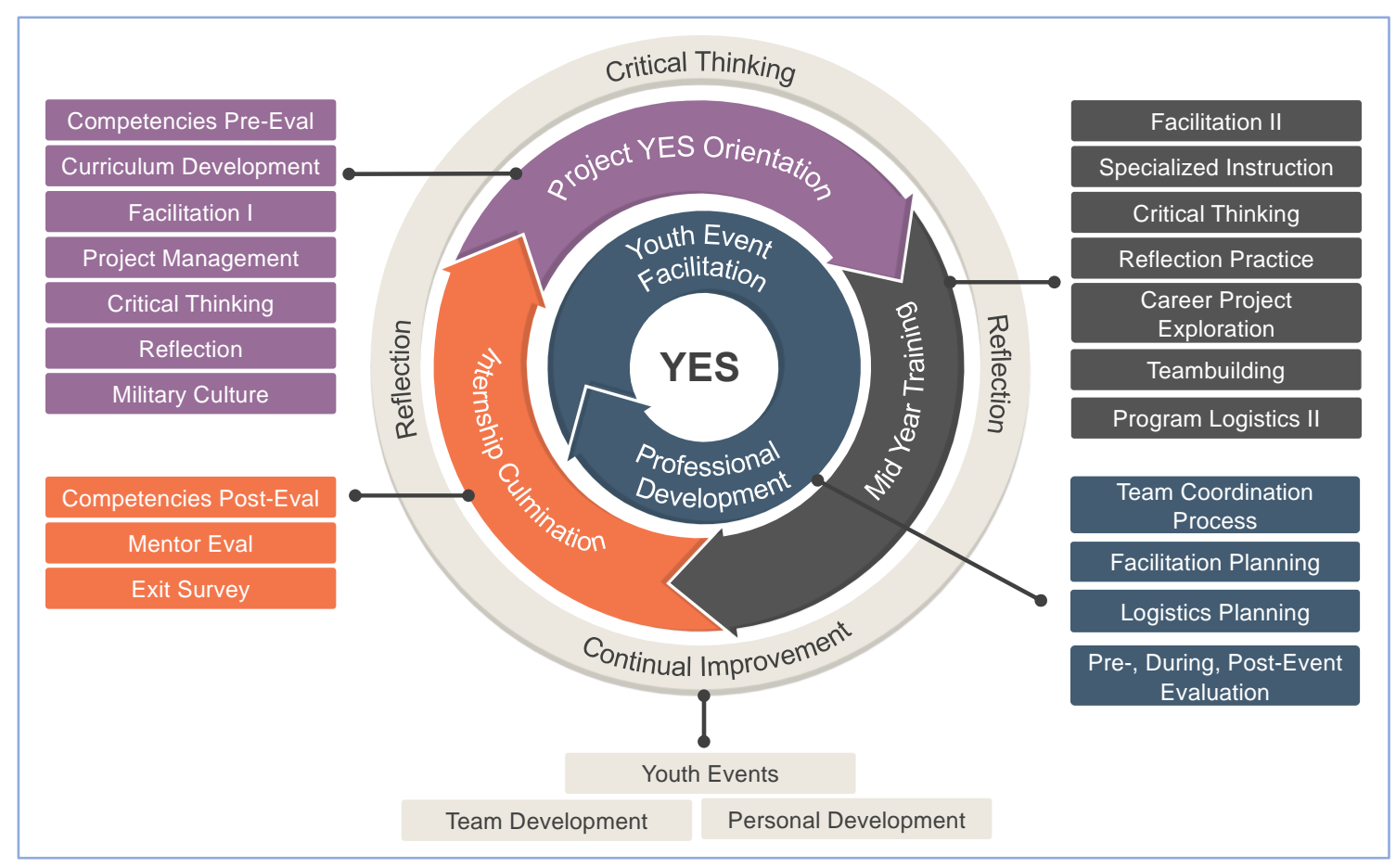

\section{Training Events}

Interns attend an 8-day on-site orientation where they participate in an initial 55 to 60 hours of training followed by an additional 24 to 30 hours during a second, mid-year training session. Attendance at both training events is required for new and returning interns. Additionally, interns participate in approximately two hours of virtual training monthly and engage in intensive learning and reflection following each event. Also, interns may request individualized mentoring at any time.

\section{Orientation and Mid-Year Training}

Face-to-face events feature opportunities for all interns to bond, gain skills, and practice critical reflection. Critical reflection using the Describe-Examine-Articulate Learning (DEAL) model (Ash \& Clayton, 2009; Paul \& Elder, 2001) is vital to the success of the Project YES! experience. The model includes objectively describing the experience or action taken, then examining the experience in the context of identified goals and learning objectives, and finally, articulating 
learning to improve practice and enhance skills. The flexibility of the DEAL model allows for processing through different lenses, which makes it ideal for training simulations, processing dilemmas, and addressing individual and team development issues.

Using the DEAL reflection model for processing activities during orientation also gives the interns opportunities to improve skills using the model so they will be ready to apply these skills when they serve at events with military youth. Interns participate in team-building and resiliency activities that are part of the youth events curriculum. They use the DEAL model to process how they have engaged in the activities as Project YES! teammates, and how they can apply the lessons learned to their work as interns, as well as to other areas of their lives outside of Project YES!. The interns also reflect on how they would facilitate the same activities and debrief youth based on expected and unexpected occurrences during a youth event and from the perspective of youth as members of military families.

In addition, interns learn about youth development, experiential learning, program planning and delivery, military families, and military organizational structure and culture. As they travel to training and youth events they also gain life skills such as time and stress management, communication, and problem-solving.

\section{Training and Internship Practice Assessment}

From initial orientation and throughout the internship experience, using on-site and online instruction, interns engage in critical reflection about issues, skills, personal practices, and peer performances. Project YES! staff monitor individual and team performance, providing periodic feedback to interns, often using observations and probing questions to further improve skills and insights. In addition, these critical reflections provide the basis for decisions on intern readiness for leadership roles.

\section{Monthly Debriefings and Additional Training}

Following each event, team leaders ( $T L$ ) prepare after action reports to summarize details for Project YES! staff. The reports include details regarding curricula used, challenges or issues encountered during the event, and assessments of growth of individual interns providing service at the event. Sources of data include observations and feedback from interns as well as military staff event hosts before, during, and after the event. These reports inform discussions of individual and team goals for events between interns and team leaders. Report results are also 
integrated into team leaders' discussions of training and programming needed to continuously renew the program. Finally, information from intern and TL reflections contribute to updates of online training supporting the intern competency-building and process management.

\section{Professional Mentor Selection and Project}

Interns are expected to identify a professional mentor within the first 3 months of their appointment. This mentor is ideally someone currently employed in the field of practice the intern is most interested in pursuing. This mentoring relationship is the focus of monthly team debrief calls and small group reflections for interns to discuss with peers any recent successes and challenges related to personal and professional growth.

An e-Portfolio system provides an online tool for mentors and mentees to work together to build a digital file of the experience to help describe personal professional growth of the intern and to create a final product that the intern can use for reference. Interns share a short presentation of their mentor experience with peers through a webinar series. This activity is an opportunity to practice presentation skills while also creating another venue for critical reflection, both personally and within the peer group.

\section{Leadership and Promotion}

Interns support Project YES! objectives through a variety of formal and informal roles as identified in Appendix A. Promotion within the formal scale is progressive and based on experience, demonstrated skill mastery, intern interest in advancement, and approval of Project YES! leadership. Each level requires a leadership professional development plan and advanced training on communication, event management, and peer management skills.

Annually, interns who have been identified as potential TLs are provided the opportunity to shadow current TL's and receive more detailed information on all aspects of the role. Prospective TL's who complete general TL training requirements then receive on-site supervision and individualized training as they plan and facilitate their first two events. Throughout their service, TLs participate in monthly conference calls focused on collaborative learning and continuing education. Many continue mentoring relationships with senior staff and peers in areas of special interest. 
Informal roles include Supply Coordinator, Travel Coordinator, Researcher, and Media Specialist. Each role requires appropriate training but roles change from event to event and interns may exercise multiple roles in the same event.

\section{Evaluation and Research Questions}

The intern Competency Evaluation and feedback from youth participants and event site coordinators were initially evaluated for program improvement and accountability but may be useful in addressing two issues in applied research:

1. (How) can young adults benefit from training and practice experiences? Since most interns already have prior academic and practical experience, will an internship result in significant growth in competencies?

2. (How) can organizations recruit and build capacities of YW to serve short-term programs, especially when programs and YW are geographically dispersed?

Research on YW competencies and expertise as well as training paradigms are nascent, and there are many challenges with recruiting and retaining staff with $21^{\text {st }}$ century skills. Lessons learned from Project YES! may help organizations address those issues and YW prepare for and sustain their careers.

\section{Methods}

Project YES! conducted surveys of interns upon entry and exit to measure program effects on intern growth. Of the 73 participants who completed internships between 2011 and 2016, 64 completed both surveys.

\section{Measurement Tools}

Each item of the Competency Evaluation was presented in quantitative (performance self-rating on a 5-item Likert scale) and qualitative (open-ended comment space on "How internship experience influenced this capacity") formats. Interns completed surveys on entry and exit from the program.

Youth and Event Coordinator surveys were designed to provide practical feedback on items of interest to funders and program leaders. Since deployment events were brief and somewhat 
varied in content, broad indicators for program climate and effects were selected as practical feedback rather than precise and in-depth measures appropriate to evaluation of extended programming.

This study was reviewed by the authors' Human Subjects Institutional Review Board and granted a waiver since it used anonymous program evaluation data.

\section{Results}

\section{Competency Evaluation: Quantitative Survey}

All items in pre/post self-rating of competencies were statistically significant, as reported in Appendix B. On 24 of 37 indicators, differences were .50 or greater on a 5-point scale. Over $90 \%$ of interns reported that they practiced 30/37 target behaviors "Quite Often" or "Very Often." Trends toward higher means and smaller standard deviations at post-program suggest consistent positive effects for all interns. Effect sizes for all behaviors exceeded the .24 threshold identified by Cuijpers (2017) as clinically significant for practice.

Areas of greatest growth include practices critical to leadership in a high-intensity environment (e.g., maintaining composure and attention, positive interaction and guidance, adapting to conditions and audiences, accepting criticism, being other-centered, relating to all cultures). Smaller, but significant improvements were evident for life skills competencies (i.e., time management, goal achievement, concentration, organization) critical to program preparation and implementation. Several competencies that might be considered character-related behaviors (i.e., credibility, reliability, respect, other-centeredness, organization, positivity) were among higher-rated competencies at first, probably because those qualities reflected selection criteria related to integrity and growth potential. During the internship these skills continued to improve. Finally, the wording of some items might have been problematic. Interns were taught to "challenge the process," but with discretion and judgment; thus "following instructions" may evoke either interpretation. Event sites had minimal technology, so use may have been limited.

\section{Intern Comments on Competencies and Climate}

The exit survey invited interns to comment on the influence of the internship on each competency. Most items garnered relatively few comments, although between 20 and 26 interns commented on five items (i.e., giving attention, asking appropriate questions, adapting 
to groups, showing peers respect, looking to help). Comments on each competency paralleled survey results, emphasizing professional skills and attitudes and processes influencing growth. Four interns gave the following responses:

- Speaking so often at Project YES! events has made me more comfortable in front of an audience.

- Planning for an event has helped me become a lot more organized.

- The largest way I believe Project YES! has influenced my listening skills is that I have learned to practice not projecting my feelings or beliefs onto someone else's experience.

- Project YES! has made me more adaptable because once a month I experience a new situation, a new town, a new team. These are changes, and I learn from every one of them.

Additionally, respondents acknowledged there was much yet to be learned:

- Time management is still something that I struggle with.

- I am still working on [constructive criticism], but if it wasn't for Project YES! I would have never even started to work on this.

\section{Emergent Themes}

Deeper analysis of intern competency survey results, represented in the responses that follow, identified three emergent themes evident across competencies: (a) personal maturation, (b) team valuation, and (c) perspectives of youth and youth work.

\section{Personal Maturation}

Interns commented on insights about self and growth through challenges:

- Through this internship I think I have been put in a variety of challenging situations. However, working with a wide variety of people has shown me that when you are calm, those around you are calm.

- Project YES! has forever changed me in aspects of adaptation and flexibility. I have always been an extremely structured person, but learning to adapt an agenda or debriefs to the needs of the youth at hand has forced me to stretch outside my comfort zone and consequently I have become extremely good at adapting to better reach others.

Receiving feedback from Project YES! interns and staff and applying those changes is a beneficial part of self-growth. 


\section{Valuing of Teamwork}

Interns discussed working through differences in personality, background, or experience much more often in relation to peers than with youth. Their comments stressed appreciating diversity and seeking synergy rather than engaging in conflict.

- I continue to work on my organizational skills but I think working with Project YES! has helped me understand the importance of being reliable and completing all tasks prior to deadlines to ensure that all team members are also able to complete their tasks on time and we are able to work better as a group overall.

- I noticed this [encouraging others to do quality work] more in my second year when we hired new interns and I worked to make sure they were comfortable in the classroom, leading events.

- I like working in a very collaborative setting. Project YES! has taught me about the importance of having different team members give their input because we all come from different experiences and backgrounds.

\section{Perspectives on Youth and Youth Work}

Interns repeatedly commented on youth stress and growth as they reflected on their own experience, suggesting that events helped youth gain support, communication and coping skills, in addition to learning from STEM and life skills activities.

- I have seen more of a need to help families after witnessing the struggles they endure.

- The ongoing events working with children on deployment issues made me work harder at being a better listener so I could try and meet the youth at the place where they were at emotionally.

- Knowing when to ask questions, when to allow youth to just think and process, and when to allow youth to come to you and offer conversation is a balance that comes with experience working with youth.

- Project YES! has taught me how to adapt to different age groups of youth and even the different attitudes of the groups.

Intern comments consistently linked growth in competencies and confidence to the program's climate of challenge and support. The comments were expressed as "stretched beyond my comfort zone," and support program staff and peers were seen as "great role models," who 
were "always there for me." Frequent mention of "learning from feedback" and "seeing other perspectives" reflected the growth mindset and critical reflection process integral to the program model. Likewise, an attitude of service with empathy was reflected in comments that interns were "motivated to work harder at listening." Finally, interns often stated or implied a deeper sense of confidence in themselves, program strategies and organization, and the PYD culture.

\section{Feedback From Program Trainers, Youth and Event Coordinators}

Intern responses are consistent with observations of program trainers who monitored interns' progress from selection through training and practice experiences, and who made decisions on interns' readiness for leadership roles (Moses, personal communication, 2019).

Youth participating in post-event surveys indicated high satisfaction with the Project YES! program, with over $85 \%$ expressing agreement or strong agreement that events were enjoyable, useful, and timely, and 95\% agreed that intern leadership was positive (Project YES!, 2018). Further, more than $95 \%$ of event hosts expressed confidence and satisfaction with interns. They provided very high ratings regarding event coordination (communication, delivery, adaptability) and meeting program objectives, and planned to request Project YES! support for future events (Project YES!, 2018).

\section{Discussion}

Project YES! trains college interns to facilitate PYD activities and provide social support to military youth during deployment events. Additionally, interns gain $21^{\text {st }}$ century workforce skills. In its initial six years, intern self-ratings and comments reflect significant growth in planning, interaction, reflection, and problem-solving skills important to youth program quality (Akiva et al., 2017; Curry et al., 2013; Gambone et al., 2002; Larson \& Walker, 2010; Pekel et al., 2018). Areas of greatest growth include practices critical to self-regulation, interaction, and adaptation in a high-intensity environment. Such skills are especially critical for new YW and typically learned through repeated practice, problem solving, and reflection with peers and mentors (Ash \& Clayton, 2009; Shockley \& Thompson, 2012; Walker \& Walker, 2012).

Smaller but significant improvements were evident for life skills that are integral to success in any $21^{\text {st }}$ century workplace (Burrus et al., 2013; Young, 2018). Character-related competencies 


\section{Preparing Capable Youth Workers: Project YES!}

that were initially among the highest-rated, were also significantly strengthened through practice. Greater growth in adaptive skills reflects program demands relative to interns' prior experience as well as need-based training priorities. Consistent with the evaluation design, areas of greatest need received the most training.

As an internship, Project YES! is not specifically designed to facilitate long-term retention in the program. However, about $95 \%$ of those hired complete the internship and approximately $60 \%$ are accepted to serve additional years with the program. Research on long-term effects of training and evaluation is ongoing.

\section{Integrated Results}

Consistent with the training, programming, and evaluation plans and practices, survey items reflect interns' "know-how," or competence to do and adapt, rather than simply "have knowledge of" or conform to prescribed roles. Comments reiterate significant skill learning identified in the post-internship survey (i.e., presenting, planning, asking questions, listening, adapting); describe the experience as challenging, confidence-building, and growth-promoting; and point to strategies (i.e., repeated practice, reflective feedback, hearing others' perspectives, support, role models, and mentoring) that influenced changes.

Cross-cutting themes emerged from intern comments. First, maturation is evident in growing composure, openness, adaptability, and confidence-capacities that are key to leadership and retention in the field (Hartje et al., 2008; Walker \& Walker, 2012). Experiences of travel; balancing work, school, and home roles; and relating to diverse peers and youth also fostered growth and maturity. Second, comments highlight the value of mutual respect and support, problem-solving, and accountability within teams. Finally, comments reflect empathy for military youth, competence in adapting to youth of different ages, and judging when and how to engage with youth (e.g., initiating or waiting on youth initiative).

Intern self-assessments are consistent with trainer and team leader observations, trends in intern retention and promotion to leadership roles, program demand and performance quality ratings from event coordinators, as well positive feedback from youth. However, program data is insufficient to determine whether internship length or leader roles influenced specific competencies or growth rates. 


\section{Preparing Capable Youth Workers: Project YES!}

Events were brief, one-time experiences offering some combination of life skills, STEM, leadership, and discussion/reflection. Youth satisfaction surveys served all age groups and focused on general reactions (i.e., enjoyable, useful, timely, positive leadership) broadly related to program quality traits such as providing a safe, supportive, skill-building, socially inclusive climate (Eccles \& Gootman, 2002). Likewise, interns' exercise of competencies and comments about interactions suggest that they nurtured the 5Cs of PYD (Bowers et al., 2010) through rapport (connection), behavioral expectations (character), support and facilitation of peer networking (caring), skill-building (competence), and encouragement and inclusion (confidence). Youth feedback levels varied from event to event, but averaged 85-95\% agreement throughout. For programs of brief duration, participant reactions or program quality data may be the best available evidence of program value (Arnold \& Cater, 2016).

Event coordinators provide organization-level assessments of program value and are accountable when program demand or satisfaction wanes. Thus, their favorable judgments and continuing invitations to provide event support suggests Project YES! training yields a highquality product.

Study results were gathered for program evaluation but also contribute to research by showing that even young adults with prior academic and practical assets gain significant benefits through intensive and extended training and leadership of youth events. Results also indicate that organizations can prepare competent staff to lead short-term programs even when programs and trainees are geographically dispersed and episodically deployed.

\section{Recommendations for Youth Worker Training}

The following recommendations are based on integrated results and Project YES! practices inferred to be the source of results.

1. Skills and attitudes provide practical behaviors and a common language (Walker \& Walker, 2012) for training cohorts. Those new to youth development especially need to become competent in what to do and how to think to create a climate for PYD. Skill sets should be tailored to program context, goals, and participants, but probably should include leadership, teamwork, program planning, management, and evaluation, as well as engagement and problem-solving (Akiva et al., 2017; Curry et al., 2013). Quality curricula and activities also facilitate skill learning and application. Such skills are valued in all $21^{\text {st }}$ century workplaces (Burrus et al., 2013; Young, 2018). 


\section{Preparing Capable Youth Workers: Project YES!}

2. Critical reflection is an essential complementary skill for understanding and applying competencies. The DEAL model facilitates insight and practice change both in-themoment and through planned debriefing (Ash \& Clayton, 2009). Reflection in teams invites multiple perspectives and collaborative action (Walker \& Walker, 2012). YW who practice critical reflection in preparation for program implementation are more adept at helping learners participate in reflection activities.

3. Embedding skill learning and reflection in youth program practice increases relevance and retention, thus maximizing transfer to new contexts. Interns who experience a climate of support and challenge (Anderson-Nathe, 2008; Gambone et al., 2002) and build assets as young adults (Scales et al., 2016) are empowered to promote program quality (Eccles \& Gootman, 2002; Smith et al., 2010) and assets needed by military youth (Easterbrooks, Ginsberg, \& Lerner, 2013). Contributing to meaningful change also enhances intern learning and motivation (Peake, Gaffney, \& Surko, 2006).

4. Intensive instruction and practice, involving repeated cycles of action and reflection in real-life contexts over an extended period, builds competence (Akiva et al., 2017; Shockley \& Thompson, 2012; Walker \& Walker, 2012). The 1- to 3-day duration of Yellow Ribbon Reintegration Program youth events limits program and relationship opportunities (as compared with extended youth programs), but enables interns to master one set of curricula or role at a time. Practice settings are similar (i.e., shortterm youth events) but also varied (i.e., no two groups or conditions the same), thus providing contexts for repeated practice as well as adjustments to novel conditions. These cycles of practice and reflection may work like interval training for physical fitness. In a similar way, the cyclical and episodic nature of the program enables interns to remain actively engaged in college, work, and social activities. Project YES! is a substantial commitment, but one that does not require students to stop and move elsewhere.

5. Opportunities for specialized learning increase YW effectiveness and retention (Hartje et al., 2008). In Project YES!, specialized topics include PYD, curricula, professionalism, military culture, military family structures, and career exploration. Diverse and expanded leadership roles (e.g., team lead, room lead) increase intern contributions to, as well as benefits from, the program. 
6. Intentional and synchronized programming, training, and evaluation plans (Little, 2014; Urban \& Trochim, 2009; Walker, 2006) enhance program effectiveness. Engaging stakeholders in use of data processes and products (Ash \& Clayton, 2009; Baughman, Boyd, \& Franz, 2012) also fosters a critically-reflective learning community.

7. Program management is efficient and effective because it is nimble and networked. Using technology to enhance and extend the reach of a core team creates opportunities to involve additional subject matter experts in content delivery and maintain ongoing connections to geographically dispersed teams. A small and stable leadership team can engage and empower interns and partners as leaders, and use technology to network, teach, manage, and evaluate.

\section{Opportunities for Future Research and Programming}

Project YES! effectively trains interns and supports military youth events, and has built capacity to refine research and programming as follows:

1. Program evaluation for accountability, with an active but informal culture of monitoring and reflection, could become a basis for more systematic evaluation on processes and products of staff development.

2. Refinements of measurement tools and processes would add to their precision, accuracy, and rigor. Compact survey descriptions of skills, for instance, do not capture the depth and breadth of competence. Targeted observations or interviews could potentially yield richer descriptions of growth than multiple open-ended questions. Expanded use of technology might facilitate enhanced collection and use of data for program improvement and research.

3. Expansion of the training and programming model to other training and programming contexts would inform and extend current results. Refinements of team leader training and the intern career project are ongoing in the current program. Training of staff or volunteers to work in a variety of community education programs might further extend and test the model. 


\section{Preparing Capable Youth Workers: Project YES!}

4. Deeper and wider investigation is needed in at least two areas: (a) program mechanisms that make training effective (i.e., What works? How and why? Under what conditions?) and (b) long-term ripple effects, including what capacities interns retain; how they apply capacities in other contexts; continuous growth in competence; and alumni impact on peers, organizations, and communities in their chosen careers.

\section{Limitations}

Study results are based on self-reports that are subject to multiple biases (Rosenman, Tennekoon, \& Hill, 2011). Since quantitative data available for this study included only response option counts for each item, we were unable to check biases. Additional evidence, especially records on incremental growth and performance by expert observers, might have corroborated, questioned, or clarified interns' perceptions. Alternatively, after intense training, practice and feedback, interns may have the most authentic perspective on their learning and growth. Moreover, though the survey was voluntary and provided the opportunity for negative ratings and comments, almost none were recorded.

Lack of individual-response data also precluded analysis of reliability. Consistent, highly positive ratings suggest the responses were not idiosyncratic, but do not establish reliability. Survey items were drawn from established protocols (e.g., Bartram, 2012; Burrus et al., 2013) and consistent with recommendations on YW competencies (e.g., Vance, 2010), suggesting a degree of content and face validity, but more research is needed to establish evidence for validity.

Intern feedback suggests the support-and-challenge approach with blended learning facilitated personal growth and effectiveness, but these mechanisms were not examined empirically. Results are promising, but may not generalize to all training or program contexts. The study employed no control or comparison groups or alternative contexts. The results further imply that skill growth derives from Project YES!, but other influences or maturation may also have contributed to overall personal and professional growth. Likewise, interns' growth bodes well for continued development and success, but these connections require further exploration. 


\section{Closing Summary}

This study explored the Project YES! internship training and practice model for building youth worker competencies, presented evidence of training effects, and discussed recommendations for practice and opportunities for improvement. Intern ratings of growth on 37 competencies critical for youth work provide explicit evidence of training effects and implicit support for professional development that integrates intensive training, embedded practice, and critical reflection in a community of practice including peers, expert mentors, and program partners. This early evidence for "knowing what" and "knowing how" invites further investigation of what else interns may gain from hands-on practice and reflection, as well as how and how long interns retain and apply competencies in other contexts.

\section{References}

Akiva, T., Li, J., Martin, K. M., Horner, C. G., McNamara A. R. (2017). Simple interactions: Piloting a strengths-based and interaction-based professional development for out-of-school time programs. Child and Youth Care Forum, 46, 285-305. http://dx.doi.org/10.1007/s10566-016$\underline{9375-9}$

Anderson-Nathe, B. (2008). So what? Now what? Implications for youth work practice. Child and Youth Services, 30(1-2), 123-128. http://dx.doi.org/10.1080/01459350802156771

Arnold, M. E. (2015). Connecting the dots: Improving extension program planning with program umbrella models. Journal of Human Sciences and Extension, 3(2), 48-67. https://www.jhseonline.com/article/view/685

Arnold, M. E., \& Cater, M. (2016). Program theory and quality matter: Changing the course of Extension program evaluation. Journal of Extension, 54(1), Article 1FEA1. https://joe.org/joe/2016february/a1.php

Ash, S. L., \& Clayton, P. H. (2009). Generating, deepening, and documenting learning: The power of critical reflection in applied learning. Journal of Applied Learning in Higher Education, 1, 25-48. https://scholarworks. iupui.edu/handle/1805/4579

Baizerman, M. (2009). Deepening understanding of managing evaluation. In D. W. Compton \& M. Baizerman (Eds.), New directions for evaluation: Managing program evaluation: Towards explicating a professional practice (pp. 87-98). San Francisco, CA: Jossey-Bass.

Bartram, D. (2012). The SHL universal competency framework. Surrey, UK: SHL Group. http://connectingcredentials.org/wp-content/uploads/2015/02/The-SHL-Universal-CompetencyFramework.pdf 
Journal of Youth Development | http://jyd.pitt.edu/ | Vol. 15 Issue 1 DOI 10.5195/jyd.2020.824

Preparing Capable Youth Workers: Project YES!

Baughman, S., Boyd, H. H., \& Franz, N. K. (2012). Non-formal educator use of evaluation results. Evaluation and Program Planning, 35, 329-336. https://doi.org/10.1016/j.evalprogplan.2011.11.008

Borden, L. M., Craig, D. L., \& Villarruel, F. A., (2004). Professionalizing youth development: The role of higher education. New Directions for Student Leadership, 104, 75-85.

https://doi.org/10.1002/yd.100

Bowers, E. P., Li, Y., Kiely, M. K., Brittian, A., Lerner, J. V., \& Lerner, R. M. (2010). The five Cs model of positive youth development: A longitudinal analysis of confirmatory factor structure and measurement invariance. Journal of Youth and Adolescence, 39, 720-735. https://doi.org/10.1007/s10964-010-9530-9

Bronfenbrenner, U., \& Morris, P. A. (2006). The bioecological model of human development. In R. M. Lerner \& W. Damon (Eds.), Handbook of child psychology: Theoretical models of human development (pp. 793-828). Hoboken, NJ, US: John Wiley \& Sons Inc.

Burrus, J., Jackson, T., Xi, N., \& Steinberg, J. (2013). Identifying the most important $21^{\text {st }}$ century workforce competencies: An analysis of the Occupational Information Network (OINET). (Research Report No. ETS RR-13-31). https://www.ets.org/Media/Research/pdf/RR-13-21.pdf

Carnegie Commission. (1992). A Matter of time: Risk and opportunity in the nonschool hours. New York: Carnegie. https://www.carnegie.org/publications/a-matter-of-time-risk-and-opportunity-in-thenonschool-hours/

Child Care Resource Center. (2019). Basic School-age Care Online.

https://childcareresourcecenter.org/event/bsac-basic-school-age-care-online/

Cuijpers, P. (2017). Four decades of outcome research on psychotherapies for adult depression: An overview of a series of meta-analyses. Canadian Psychology, 58, 7-19. http://dx.doi.org/10.1037/cap0000096

Curry, D., Eckles, F., Stuart, C., Schneider-Munoz, A. J., \& Qaqish, B. (2013). National certification for child and youth workers: Does it make a difference? Children and Youth Services Review, 35, 1795-1800. http://dx.doi.org/10.1016/j.childyouth.2013.08.005

Durlak, J. A., Weissberg, R. P., \& Pachan, M. (2010). A meta-analysis of after-school programs that promote personal and social skills in children and adolescents. American Journal of Community Psychology, 45, 294-309. http://dx.doi.org/10.1007/s10464-010-9300-6

Eccles, J., \& Gootman, J. A. (Eds., 2002). Community programs to promote youth development. Washington, DC: National Academy Press.

Enfield, R. P., Schmitt-McQuitty, L., \& Smith, M. H. (2007). The development and evaluation of experiential learning workshops for staff and volunteers. Journal of Extension, 45(1), 1 FEA2. https://www.joe.org/joe/2007february/a2.php 
Journal of Youth Development | http://jyd.pitt.edu/ | Vol. 15 Issue 1 DOI 10.5195/jyd.2020.824 Preparing Capable Youth Workers: Project YES!

Easterbrooks, M. A., Ginsburg, K., \& Lerner, R. M. (2013). Resilience among military youth. Future of Children, 23(2), 99-120. https://doi.org/10.1353/foc.2013.0014

Gambone, M. A., Klem, A. M., \& Connell, J. P. (2002). Finding out what matters for youth: Testing key links in a community action framework for youth development. Philadelphia, PA: Youth Development Strategies. http://www.ydsi.org/YDSI/pdf/WhatMatters.pdf

Garst, B. A., Weston, K. L., Bowers, E. P., \& Quinn, W. H. (2019). Fostering youth leader credibility: Professional, organizational, and community impacts associated with completion of an online master's degree in youth development leadership. Children and Youth Services Review, 96, 1-9. https://doi.org/10.1016/j.childyouth.2018.11.019

Hartje, J. A., Evans, W. P., Killian, E. S., \& Brown, R. (2008). Youth worker characteristics and selfreported competency as predictors of intent to continue working with youth. Child and Youth Care Forum, 37, 27-41. http://dx.doi.org/10.1007/s10566-007-9048-9

Jonas, S. (2012). Embedding and sustaining youth worker core competencies in out-of-school time programs. In D. Fusco (Ed.), Advancing youth work: Current trends, critical questions (pp. 1526). New York: Routledge.

Larson, R. W., Rickman, A. N., Gibbons, C. M., \& Walker, K. C. (2009). Practitioner expertise: Creating quality within the daily tumble of events in youth settings. New Directions in Youth Development, 121, 71-88. https://doi.org/10.1002/yd.297

Larson, R. W., \& Walker, K. C. (2010). Dilemmas of practice: Challenges to program quality encountered by youth program leaders. American Journal of Community Psychology, 45, 338-349. https://doi.org/10.1007/s10464-010-9307-z

Little, P. M. (2014). Evaluating afterschool programs. New Directions for Youth Development, 144(Winter), 119-132. https://doi.org/10.1002/yd.20117

Mattingly, M., Stuart, C., \& VanderVen, K. (2010). Competencies for professional child and youth work practitioners. (Revised ed.). College Station, TX: Child and Youth Care Certification Board.

Mahoney, J. L., Parente, M. E., \& Zigler, E. F. (2009). Afterschool programs in America: Origins, growth, popularity, and politics. Journal of Youth Development, 4(3).

\section{https://doi.org/10.5195/jyd.2009.250}

National Afterschool Association. (2011). Core knowledge and competencies for afterschool and youth development professionals. Online at https://naaweb.org/resources/core-competencies

Paul, R. P., \& Elder, L. (2001). The miniature guide to critical thinking. Santa Rosa, CA: Foundation for Critical Thinking.

Peake, K., Gaffney, S., \& Surko, M. (2006). Capacity-building for youth workers through communitybased partnerships. Journal of Public Health Management and Practice, 12(Suppl.), S65-S71. https://doi.org/10.1097/00124784-200611001-00013 
Pekel, K., Roehlkepartain, E. C., Syvertsen, A. K., Scales, P., Sullivan, T. K., \& Sethi, J. (2018). Finding the fluoride: Examining how and why developmental relationships are the active ingredient in interventions that work. American Journal of Orthopsychiatry, 88(5), 493-502.

http://dx.doi.org.prox.lib.ncsu.edu/10.1037/ort0000333

Project YES! (2018). Monthly reports on program performance. Raleigh, NC: Project YES!

Rosenman, R., Tennekoon, V., \& Hill, L. G. (2011). Measuring bias in self-reported data. International Journal of Behavioral Healthcare Research, 2(4), 320-332.

http://dx.doi.org/10.1504/IJBHR.2011.043414

Scales, P., Benson, P. L., Oesterle, S., Hill, K. G., Hawkins, J. D., \& Travis, J. P. (2016). The dimensions of successful young adult development: A conceptual and measurement framework. Applied Developmental Science, 20(3), 150-174. http://dx.doi.org/10.1080/10888691.2015. 1082429

Shek, D. T, L., \& Yu, L. (2016). Cognitive competence: A key positive youth development construct for university students. International Journal of Disabilities in Human Development, 15(2), 135-142. DOI 10.1515/ijdhd-2016-0702

Shockley, C. \& Thompson, A. (2012). Youth workers in college: A replicable model for professional development. Children and Youth Services Review, 34, 735-739. http://dx.doi.org/10.1016/j.childyouth.2011.12.019

Smith, C., Peck, S. C., Denault, A., Blazevski, J., \& Akiva, T. (2010). Quality at the point of service: Profiles of practice in after-school settings. American Journal of Community Psychology, 45, 358369. https://dx.doi.org/10.1007/s10464-010-9315-z

Starr, E., Yohalem, N., \& Gannett, E. (2009). Youth worker core competencies: A review of existing frameworks and purposes. Washington, DC: Next Generation Youth Work Coalition.

Stone, B., \& Rennekamp, R. (2004). New foundations for the 4-H youth development profession: 4-H professional research, knowledge, and competencies study, 2004. Conducted in cooperation with the National 4-H Professional Development Task Force. National 4-H Headquarters, CSREES, USDA.

Urban, J. B. \& Trochim, W. M. (2009). The role of evaluation in research-practice integration: Working toward the "golden spike." American Journal of Evaluation, 30(4), 538-553.

\section{https://doi.org/10.1177/1098214009348327}

Vance, F. (2010). A comparative analysis of competency frameworks for youth workers in the out-ofschool field. Child and Youth Care Forum, 39, 421-441. http://dx.doi.org/10.1007/s10566-0109116-4

Velez, G. S. \& Giner, G. R. (2015). Effects of business internships on students, employers, and higher education institutions: A systematic review. Journal of Employment Counseling, 52, 121-130. https://doi.org/10.1002/joec.12010 
Journal of Youth Development | http://jyd.pitt.edu/ | Vol. 15 Issue 1 DOI 10.5195/jyd.2020.824

\section{Preparing Capable Youth Workers: Project YES!}

Walker, J. A. (2003). The essential youth worker. In F. A. Villarruel, D. F. Perkins, L. M. Borden, \& J. G. Keith (Eds.), Community youth development: Programs, policies, and practices (pp. 373-393). Thousand Oaks, CA: Sage.

Walker, J. (2006). Intentional youth programs: Taking theory to practice. In D. A. Blyth \& J. A. Walker (Eds.), New Directions for Youth Development (pp. 75-92). https://doi.org/10.1002/yd.194

Walker, J., \& Walker, K. (2012). Establishing expertise in an emerging field. In D. Fusco (Ed.), Advancing youth work: Current trends, critical questions (pp. 39-51). New York: Routledge.

Walker, K., \& Gran, C. (2010). Beyond core competencies: Practitioner expertise as a critical component of quality. Minneapolis: University of Minnesota Extension Center for Youth Development. https://conservancy.umn.edu/handle/11299/195259

Young, R. (2018). Soft skills: The primary predictor of success in academics, career, and life. https://www.pairin.com/2018/07/13/soft-skills-primary-predictor-success-academics-career-life/ 


\section{Appendix A}

\section{Project YES! Formal and Informal Roles}

\section{Formal Roles}

Senior Team Lead (STL). An experienced team lead who has been with Project YES! For at least 2 years.

- Capable of serving as a team lead at all levels of Project YES! events

- Participate in identifying and training team leads

Team Lead (TL). An experienced intern responsible for the overall team leadership and management at Project YES! Events.

- Coordinates event agendas and logistics with event host or point of contact (POC)

- Assigns formal and informal roles and responsibilities to event team members

- Monitors program delivery during Project YES! events and makes all necessary adjustments and changes

- Leads team-level reflection and critical thinking sessions

- Selects Room Leads (as necessary) for larger events

- Provides team-level training and education during orientation and mid-year training

- Fulfills all team-level administrative, logistical, and reporting requirements

Senior Room Lead (SRL). An experienced room lead qualified to support any Project YES! event.

- Performs all responsibilities of a room leader for all sizes of events supporting pre-, during, and/or post-deployment

- Liaison between STL/TL and Project YES! interns in their assigned room

- Assists in training new Room Leads

Room Lead $(R L)$. Liaison between TL and staff interns during event planning and program delivery.

- Facilitates delivery of daily agendas (events, reflections, sessions, de-briefs, etc.)

- Monitors and enforces room safety procedures

- Coordinates logistics (meals, breaks, guest speakers, etc.) with event POCs, Project YES! team and childcare providers

- Enforces youth accountability procedures 
- Assists TL, event POC, or childcare providers with all duty-to-report, and/or safety/accident reporting requirements

Staff Intern (SI). Responsible for event preparation and onsite event facilitation.

- Actively participates in all pre-, during, and post-event individual and team-level activities

- Facilitates approved leadership development, life skills, and resilience curriculum activities within the Project YES! event theme

- Collaborate with TL/RL to create classroom management action plans

\section{Informal Roles}

Supply Coordinator. Facilitates assessment and of all supplies required to support approved event agenda activities.

Travel Coordinator. Identifies team-level travel requirements and develops a comprehensive travel plan.

Researcher. Creates a local area data sheet identifying key areas of interest such as weather conditions, lodging services, dining options, and local area interest items.

Media Specialist. Takes photos, videos, etc. as appropriate and/or approved by Project YES! leadership and event coordinators. 
Journal of Youth Development | http://jyd.pitt.edu/ | Vol. 15 Issue 1 DOI 10.5195/jyd.2020.824

Preparing Capable Youth Workers: Project YES!

\section{Appendix B}

\section{Competence Evaluation: Cumulative Evidence From Pre-Program Tests and Exit Surveys}

\begin{tabular}{|c|c|c|c|c|c|c|c|}
\hline \multirow[b]{2}{*}{$\begin{array}{l}\text { Target behavior } \\
\text { (descriptor, acronym) }\end{array}$} & \multicolumn{2}{|c|}{ Pre-training } & \multicolumn{2}{|c|}{ Post-training } & \multicolumn{3}{|c|}{ Comparison } \\
\hline & $M$ & $S D$ & $M$ & $S D$ & $\begin{array}{l}t \text {-test/ } \\
p \text {-value }\end{array}$ & MD & ES \\
\hline Adapt approach for new challenges & 3.72 & .786 & 4.66 & .470 & $16.05^{* *}$ & .94 & $1.452 * *$ \\
\hline Learn and grow from mistakes, challenges & 3.80 & .739 & 4.66 & .479 & $15.93 * *$ & .86 & $1.381^{* *}$ \\
\hline Select and use instructional materials & 3.59 & .706 & 4.47 & .590 & $21.00 * *$ & .88 & $1.353 * *$ \\
\hline Aware of signs of stress in self and others & 3.72 & .629 & 4.52 & .591 & $15.72 * *$ & .80 & $1.311^{* *}$ \\
\hline Maintain composure under challenge & 3.72 & .766 & 4.55 & .532 & $14.52 * *$ & .83 & $1.259 * *$ \\
\hline Ask appropriate questions, right time & 3.52 & .776 & 4.28 & .548 & $11.63 * *$ & .76 & $1.131^{* *}$ \\
\hline Manage conflict effectively & 3.42 & .752 & 4.17 & .579 & $12.73 * *$ & .67 & $1.118^{* *}$ \\
\hline Give full attention to what others say & 3.97 & .666 & 4.63 & .776 & $10.97 * *$ & .66 & $1.105^{* *}$ \\
\hline Know where to find answers to questions & 3.81 & .687 & 4.48 & .534 & $11.36^{* *}$ & .67 & $1.089 * *$ \\
\hline Pay attention to details, thorough in tasks & 3.88 & .678 & 4.53 & .503 & $10.97 * *$ & .65 & $1.089 * *$ \\
\hline Do what I say I am going to do & 4.33 & .592 & 4.83 & .449 & $5.16 * *$ & .50 & $1.084^{* *}$ \\
\hline Relate well to people of different cultures & 3.75 & .756 & 4.48 & .591 & $13.20 * *$ & .73 & $1.076 * *$ \\
\hline Adapt lessons to needs of a group & 3.78 & .806 & 4.56 & .588 & $15.00 * *$ & .78 & $1.056 * *$ \\
\hline Follow instructions without challenging & 3.98 & .845 & 4.33 & .745 & $4.39 * *$ & .35 & $1.046^{* *}$ \\
\hline Communicate information clearly & 3.78 & .723 & 4.47 & .590 & $11.77^{* *} *$ & .69 & $1.046^{* *}$ \\
\hline See impact of your behavior on others & 3.89 & .799 & 4.61 & .607 & $12.69 * *$ & .72 & $1.014^{* *}$ \\
\hline
\end{tabular}


Journal of Youth Development | http://jyd.pitt.edu/ | Vol. 15 Issue 1 DOI 10.5195/jyd.2020.824

Preparing Capable Youth Workers: Project YES!

(Continued)

\begin{tabular}{|c|c|c|c|c|c|c|c|}
\hline \multirow[b]{2}{*}{$\begin{array}{l}\text { Target behavior } \\
\text { (descriptor, acronym) }\end{array}$} & \multicolumn{2}{|c|}{ Pre-training } & \multicolumn{2}{|c|}{ Post-training } & \multicolumn{3}{|c|}{ Comparison } \\
\hline & $M$ & $S D$ & $M$ & $S D$ & $\begin{array}{l}\text { t-test/ } \\
\text { p-value }\end{array}$ & MD & ES \\
\hline Accept constructive criticism calmly & 3.55 & .975 & 4.41 & .706 & $15.93 * *$ & .86 & $1.010 * *$ \\
\hline $\begin{array}{l}\text { See change as an opportunity to learn and } \\
\text { grow }\end{array}$ & 4.03 & .908 & 4.72 & .487 & $9.82 * *$ & .69 & $.947 * *$ \\
\hline Comfortable making presentations & 3.63 & 1.03 & 4.42 & .708 & $12.51 * *$ & .79 & $.894 * *$ \\
\hline Effective at time management & 3.61 & .809 & 4.27 & .672 & $10.97 * *$ & .66 & $.888^{* *}$ \\
\hline Consistently achieve project goals & 3.92 & .65 & 4.47 & .59 & $8.72 * *$ & .44 & $.887 * *$ \\
\hline Look for ways to use technology in projects & 3.09 & .921 & 3.83 & .827 & $13.20 * *$ & .74 & $.845^{* *}$ \\
\hline Keep track of and organize information & 3.94 & .814 & 4.53 & .563 & $9.60 * *$ & .59 & $.830 * *$ \\
\hline Focus on others' needs and satisfaction & 4.00 & .563 & 4.44 & .614 & $7.00 * *$ & .44 & $.747 * *$ \\
\hline Encourage others to do quality work & 4.00 & .735 & 4.50 & .617 & $7.94 * *$ & .50 & $.737 * *$ \\
\hline Like learning new systems and processes & 3.55 & .853 & 4.16 & .801 & $9.91 * *$ & .60 & $.737 * *$ \\
\hline Write materials for different audiences & 3.56 & 639 & 4.06 & .732 & $7.94 * *$ & .50 & $.728 * *$ \\
\hline $\begin{array}{l}\text { Show respect for the views } \\
\text { of team peers }\end{array}$ & 4.27 & .623 & 4.67 & .565 & $6.57 * *$ & .40 & $.673^{* *}$ \\
\hline $\begin{array}{l}\text { Acting responsibly to community, } \\
\text { environment }\end{array}$ & 4.23 & 636 & 4.61 & .061 & $6.15^{* *}$ & .38 & $.668^{* *}$ \\
\hline $\begin{array}{l}\text { Others see my positive, cooperative } \\
\text { approach }\end{array}$ & 4.13 & .577 & 4.58 & .773 & $5.45^{* *}$ & .45 & $.660 * *$ \\
\hline Concentrate on tasks without distractions & 3.66 & .801 & 4.11 & .645 & $7.26 * *$ & .45 & $.619 * *$ \\
\hline
\end{tabular}


Journal of Youth Development | http://jyd.pitt.edu/ | Vol. 15 Issue 1 DOI 10.5195/jyd.2020.824

Preparing Capable Youth Workers: Project YES!

\section{(Continued)}

\begin{tabular}{|l|c|c|c|c|c|c|c|}
\hline & \multicolumn{2}{|c|}{ Pre-training } & \multicolumn{2}{|c|}{ Post-training } & \multicolumn{3}{c|}{ Comparison } \\
\hline $\begin{array}{l}\text { Target behavior } \\
\text { (descriptor, acronym) }\end{array}$ & $M$ & $S D$ & $M$ & $S D$ & $\begin{array}{c}\text { t-test/ } \\
\text { p-value }\end{array}$ & MD & ES \\
\hline Look for ways to help people & 4.31 & .732 & 4.70 & .525 & $6.356^{* *}$ & .39 & $.612^{* *}$ \\
\hline Others see me as reliable, dependable & 4.34 & .648 & 4.67 & .473 & $5.55^{* *}$ & .33 & $.582^{* *}$ \\
\hline Generally, I have a positive attitude & 4.20 & .76 & 4.56 & .500 & $5.58^{* *}$ & .30 & $.560^{* *}$ \\
\hline Others believe I project credibility & 3.95 & .547 & 4.28 & .678 & $5.55^{* *}$ & .33 & $.536^{* *}$ \\
\hline Share what I know about technology & 3.52 & 1.09 & 4.00 & .926 & $7.69 * *$ & .48 & $.473^{*}$ \\
\hline Respond quickly to others' feedback & 3.67 & .818 & 4.05 & .862 & $6.15^{* *}$ & .38 & $.426 *$ \\
\hline
\end{tabular}

Note. $M=$ Mean score, $S D=$ Standard Deviation, $M D=$ Mean difference between pre- and post-program test scores, $\mathrm{ES}=$ Cohen's $d$ effect size.

Paired samples $t$-test and effect size $p$-value referents: $* p<.01, * * p<.001$. 